\title{
Comment on "Application of PK/PD Modeling in Veterinary Field: Dose Optimization and Drug Resistance Prediction"
}

\author{
Anna Benini and Guido Francesco Fumagalli \\ Department of Diagnostics and Public Health, Pharmacology Section, University of Verona, Verona, Italy \\ Correspondence should be addressed to Anna Benini; anna.benini@univr.it
}

Received 17 May 2017; Accepted 3 July 2017; Published 18 July 2017

Academic Editor: Abdelwahab Omri

Copyright (C) 2017 Anna Benini and Guido Francesco Fumagalli. This is an open access article distributed under the Creative Commons Attribution License, which permits unrestricted use, distribution, and reproduction in any medium, provided the original work is properly cited.

While performing a literature search in PubMed on application of PK/PD parameters in veterinary, we found the review "Application of PK/PD Modeling in Veterinary Field: Dose Optimization and Drug Resistance Prediction" by Ahmad et al. published in BioMed Research International [1]. This review deals with antimicrobial drugs used in veterinary and with pharmacokinetic/pharmacodynamic modeling developed to maximize drug efficacy, establish appropriate dosage regimens, and reduce side effects.

Although the review is interesting and well-articulated, we disagree with the content of Table 3.

In that table (page 5) the different classes of antimicrobial drugs are divided into two groups. For group 1 the common criterion is the AUC/MIC ratio $\left(C_{\max } / \mathrm{MIC}\right.$ or $\left.\mathrm{AUC}_{0-24} / \mathrm{MIC}\right)$. For group 2, $\% T_{>\mathrm{MIC}}$ is the classification criterion. The table is indeed inspired by a previous publication by Martinez et al. published in 2012 [2]. The grouping of antibiotics based on PK/PD parameters is also discussed by Martinez et al. in 2014 [3], by Ambrose et al. in 2007 [4], and by several other authors.

In all cases Ketolides, Lincosamides (clindamycin), and Glycopeptides (Vancomycin) are identified by the AUC/MIC ratio as $\mathrm{PK} / \mathrm{PD}$ reference parameters. They should therefore be included in group 1 and not in group 2 as done by the authors of the review published in your journal.

Those antibiotics have effects that are time dependent but this is not a sufficient criterion to apply as PK/PD criterion $\% T_{>M I C}$. Indeed, antimicrobial efficacy of Vancomycin,
Clindamycin, and Telithromycin is related to $C_{\max } / \mathrm{MIC}$ or $\mathrm{AUC}_{0-24} / \mathrm{MIC}$.

It is well known that antimicrobial agents that interact with the cell wall usually display time-dependent bactericidal activity that correlates with $\% T_{>\mathrm{MIC}}$. On the contrary, agents that inhibit protein synthesis have a concentrationdependent bactericidal action which correlates well with the AUC/MIC ratio. Thus, Ketolides and Lincosamides are usually included in group 1 and not 2 (see $[2,3]$ ).

However it should be noted that also agent acting on the bacterial wall may be included in group 1 (bactericidal action correlating more with the AUC/MIC ratio than with the $\left.\% T_{>\text {MIC }}\right)$. In the case of Vancomycin, whose half-life and prolonged PAE fully satisfy the condition time-dependent bactericidal effect, the real predictor of efficacy is more closely related to plasma concentration $[5,6]$.

The implication of including an agent in group 1 or 2 is definition of the therapy in terms of dose and pharmacokinetics. Including one agent in one group instead of the other is not trivial and may lead to therapeutic errors. We therefore strongly recommend that the organization of Table 3 is revised according to our observation and to the abundant literature.

\section{Conflicts of Interest}

The authors declare that there are no conflicts of interest regarding the publication of this paper. 


\section{References}

[1] I. Ahmad, L. Huang, H. Hao, P. Sanders, and Z. Yuan, "Application of PK/PD modeling in veterinary field: dose optimization and drug resistance prediction," BioMed Research International, vol. 2016, Article ID 5465678, 12 pages, 2016.

[2] M. N. Martinez, M. G. Papich, and G. L. Drusano, "Dosing regimen matters: the importance of early intervention and rapid attainment of the pharmacokinetic/pharmacodynamic target," Antimicrobial Agents and Chemotherapy, vol. 56, no. 6, pp. 2795-2805, 2012.

[3] M. Martinez, J. Blondeau, C. E. Cerniglia et al., "Workshop report: the 2012 antimicrobial agents in veterinary medicine: exploring the consequences of antimicrobial drug use: a 3-D approach," Journal of Veterinary Pharmacology and Therapeutics, vol. 37, no. 1, pp. 1-16, 2014.

[4] P. G. Ambrose, S. M. Bhavnani, C. M. Rubino et al., "Pharmacokinetics-pharmacodynamics of antimicrobial therapy: it's not just for mice anymore," Clinical Infectious Diseases, vol. 44, no. 1, pp. 79-86, 2007.

[5] C. Giuliano, K. K. Haase, and R. Hall, "Use of vancomycin pharmacokinetic-pharmacodynamic properties in the treatment of MRSA infections," Expert Review of Anti-Infective Therapy, vol. 8, no. 1, pp. 95-106, 2010.

[6] A. Barbour, F. Scaglione, and H. Derendorf, "Class-dependent relevance of tissue distribution in the interpretation of antiinfective pharmacokinetic/pharmacodynamic indices," International Journal of Antimicrobial Agents, vol. 35, no. 5, pp. 431438, 2010 . 

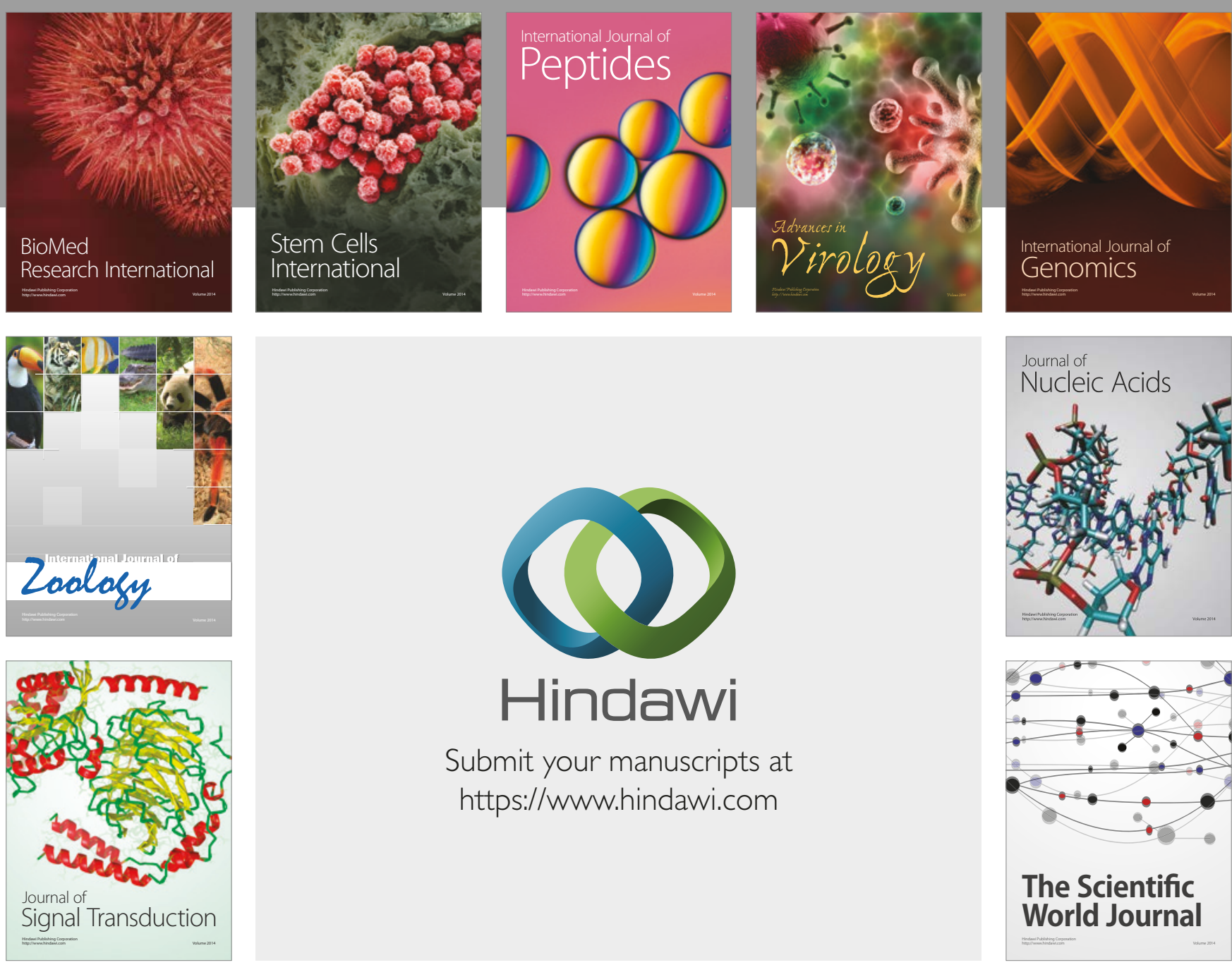

Submit your manuscripts at

https://www.hindawi.com
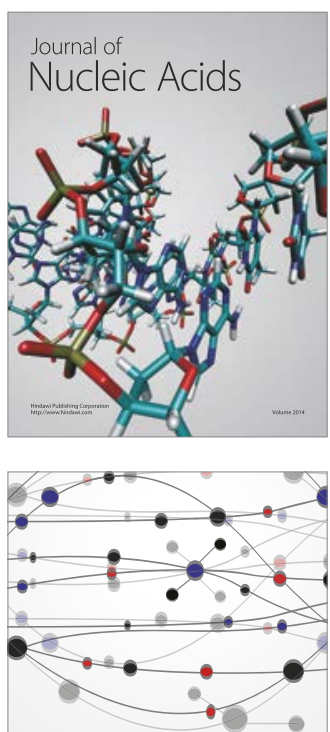

The Scientific World Journal

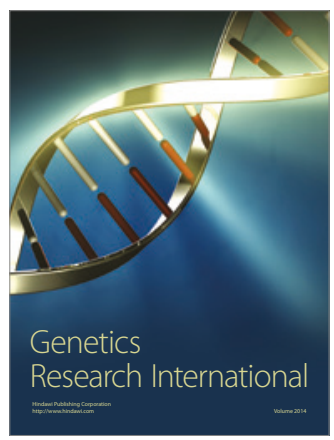

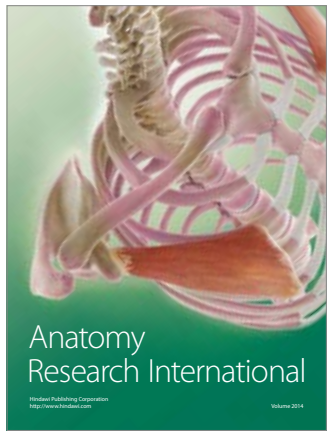

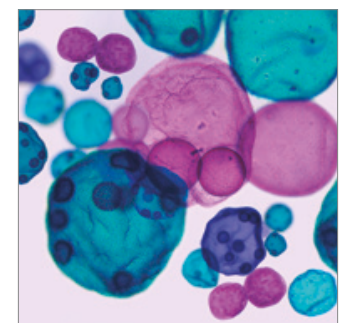

International Journal of Microbiology
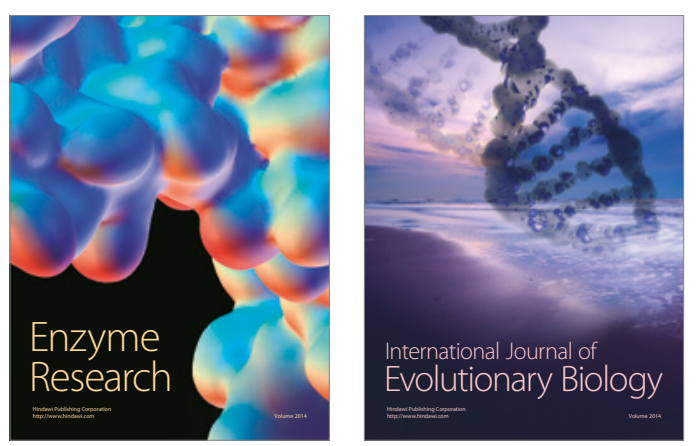
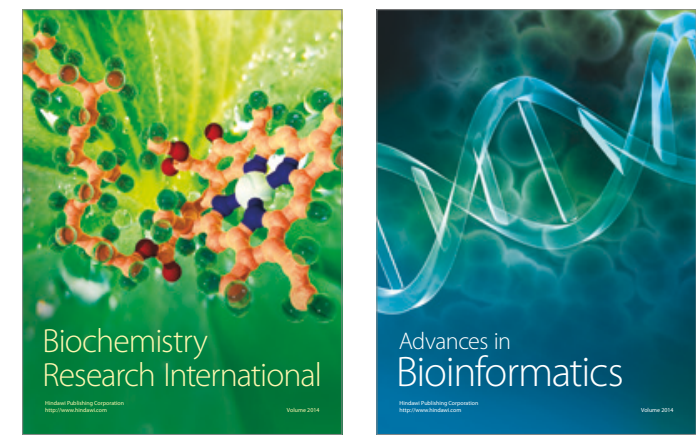

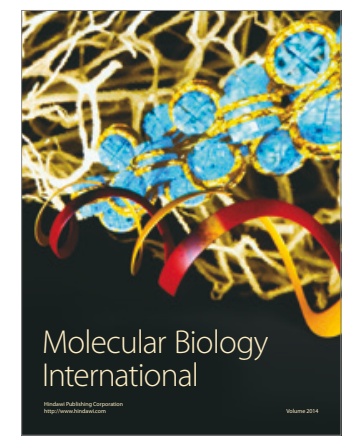

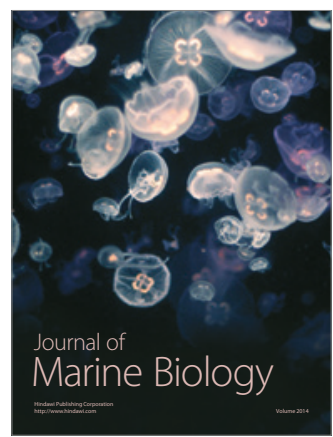

